\title{
Risk and Protective Factors for Psychopathology Among Older versus Younger Adults After the 2004 Florida Hurricanes
}

\author{
Ron Acierno, Ph.D., Kenneth J. Ruggiero, Ph.D., \\ Dean G. Kilpatrick, Ph.D., Heidi S. Resnick, Ph.D., \\ Sandro Galea, M.D., Dr.P.H.
}

\begin{abstract}
Objective: Previous research demonstrates increased resiliency to psychopathology after disasters among older adults. However, little is known about differences in age-based risk and protective factors for postdisaster mental illness. Method: The authors used random-digit dialing methodology to survey 1,130 older adults (60+ years) and 413 younger adults residing in Florida counties directly affected by the 2004 burricanes. Assessed risk and protective factors included demographics, social support, displacement, incurred dollar losses, perceived positive outcomes, and selfrated health status. Outcome variables included symptom counts of Diagnostic and Statistical Manual of Mental Disorders, Fourth Edition-defined posttraumatic stress disorder (PTSD), major depressive disorder (MDD), and generalized anxiety disorder (GAD). Results: Older adults reported fewer symptoms of PTSD, MDD, and GAD. Explanatory risk variables accounted for large proportions of variance, but differed in meaningful ways across age groups. Conclusion: Although older adults are less symptomatic, their psychologic reactions appear more closely connected to economic consequences of disasters. (Am J Geriatr Psychiatry 2006; 14:1051-1059)
\end{abstract}

Key Words: Risk, older adult, PTSD, depression, GAD, disaster

$\mathrm{T}^{\mathrm{s}}$ he associated impact of advanced age on risk of negative mental and physical health outcomes after natural disasters appears to be protective with respect to posttraumatic stress disorder (PTSD) and depression. ${ }^{1,2}$ This finding is somewhat counterintuitive given the fact that older adults are particularly susceptible to injury and health-related complications after such events ${ }^{3}$ and that these negative physical outcomes themselves are often predictive of emotional problems. That is, in light of increased risk of negative postdisaster physical health effects, it is interesting that increased age is associated with

Received October 20, 2005; revised January 20, 2006; accepted March 17, 2006. From the Medical University of South Carolina, Charleston, SC (RA, KJR, DGK, HSR), and the University of Michigan School of Public Health, Ann Arbor, MI (SG). Send correspondence and reprint requests to Dr. Ron Acierno, National Crime Victims Research and Treatment Center, Department of Psychiatry and Behavioral Sciences, Medical University of South Carolina, P.O. Box 250852, Charleston, SC 29425. e-mail: acierno@musc.edu

(c) 2006 American Association for Geriatric Psychiatry 
lower risk of psychopathology and may suggest that different risk and protective factors are operating within each age group.

Considering the protective effects of age with respect to psychopathology, in a review of the empiric literature by Norris and colleagues that included 60,000 disaster victims, ${ }^{4}$ older adults were less likely to experience serious postdisaster psychologic problems than younger adults in 12 of 14 samples. Moreover, in a study of New York City residents after the terrorist attacks of September 11, 2001, older adults reported the lowest levels of PTSD symptomatology of any age group. ${ }^{5}$ However, protective effects of age may vary with culture to some extent. Norris' group ${ }^{6}$ also studied three different groups of disaster victims, including U.S. citizens after hurricane Andrew (non-Hispanic $\mathrm{N}=270$ ), Mexican citizens after hurricane Paulina $(\mathrm{N}=200)$, and Polish citizens after the 1997 flood $(\mathrm{N}=285)$ and found that older age was protective for U.S. and Mexican participants, but was a risk factor for Polish participants. Of course, in this study, cultural differences were confounded by the nature of the stress event; nonetheless, the protective factor of age was apparent for two of three groups.

General (as opposed to age-specific) postdisaster risk factor analyses have focused on both personbased and event characteristics. Considering personbased characteristics, female gender, minority ethnic or racial status, and low social support were associated with increased likelihood of developing PTSD or major depressive disorder (MDD) after exposure to potentially traumatic events. ${ }^{1-4,7}$ With respect to aspects of the traumatic stressor, direct proximal exposure to, or witnessing of stressors, perceived life threat during exposure, significant economic loss, and displacement after stressors all have been associated with increased potential of developing emotional problems. ${ }^{4,7}$

To date, very little research has focused on agespecific analysis of risk factors with adult samples. However, initial work in this area with victims of interpersonal violence indicated some differences between older and younger adults, with lower income and poor health status predictive of negative outcomes in younger but not older participants. ${ }^{1}$ As mentioned, however, this was a sample of victims of physical and sexual assault and was comprised exclusively of female participants. Thus, the generaliz- ability of this study's findings to postdisaster effects in less restricted populations is potentially limited.

Although the existing literature indicates that age is consistently found to be a protective factor against developing emotional problems secondary to exposure to potentially traumatic events, little research exists to specify the nature of age-based risk factors for negative outcomes. The present study used representative samples of older and younger adults affected by the 2004 Florida hurricanes to 1) examine age-based differences in PTSD, depression, and generalized anxiety symptom levels; and 2) identify potential risk and protective factors for these outcomes as a function of age group.

\section{METHODS}

\section{Recruitment}

Data were collected from 1,130 older adults (aged $60+$ years) and 413 younger adults (aged 18-59 years) residing in households with telephones in Florida counties that were in the direct path of one or more of the 2004 hurricanes. We oversampled adults aged 60 years and over to assure that sufficient numbers of cases for each form of psychopathology would be available for risk analyses in this age group. Random-digit dial (RDD) techniques were used to screen households for eligibility. Inclusion criteria were specified as aged 18 years or older, English- or Spanish-speaking, and clearly able to give informed consent to a professional interviewer with specific training regarding provision and collection of informed consent. Obvious evidence of an inability to complete survey questions or evidence of a misunderstanding of the respondent selection process during initial contact through the "most recent birthday method," in which the participant who most recently celebrated a birthday (and who spoke English or Spanish and was over age 18) was selected for participation, resulted in exclusion from the study.

With respect to RDD procedures, a multistage process was used to select the sampling frame. Telephone exchanges in Florida counties that were declared disaster zones were identified. Next, we systematically selected residential telephone ex- 
changes within the primary sampling units. One telephone number for each primary sampling unit was randomly selected from telephone directories for those counties affected by the Florida hurricanes and declared disaster areas. The selected numbers were then altered by dropping the last two digits (in central cities and suburban areas) or the last three digits (rural areas) and replacing them with randomly generated numbers. As many two- or three-digit randomly selected numbers were appended as needed until a working residential number was reached or until an interview was completed. Next, RDD was used to select a telephone number within identified exchanges. When we reached a residence with multiple eligible respondents, we randomly selected one eligible respondent within each household as the designated respondent (by most recent birthday method).

Each nonanswered telephone call was redialed up to five times at different times of the day on different days. Once a residential contact was established, the interviewer identified a designated respondent for the interview. If a designated respondent refused to be interviewed, a new telephone number was generated and the screening process was repeated. If initial contact was made with the designated respondent, but the time was inconvenient, interviewers set up appointments at the respondent's convenience.

The original sampling frame consisted of the 38 Florida counties that were exposed to hurricaneforce winds. ${ }^{8}$ Data from five counties (Bay, Broward, Holmes, St. Johns, and Washington) were not used in this study because it became evident from participant reports that hurricane-force winds affected a relatively small percentage of the area and population in those counties and sampling was terminated. Interviews were conducted between April 5 and June 12, 2005. The Institutional Review Board of the Medical University of South Carolina approved this study. Informed consent was obtained verbally from participants.

\section{Study Instrument}

A structured computer-assisted telephone interview (CATI) administered in English or Spanish was used to collect information on basic demographics, hurricane-related impact, social support, health status, and Diagnostic and Statistical Manual of Mental
Disorders, Fourth Edition (DSM-IV) symptoms of PTSD, generalized anxiety disorder (GAD), and depression. Through CATI, each question in the highly structured telephone interview appears on a computer screen and is read verbatim to respondents. Use of CATI incorporates complex skip patterns, eliminates postinterview coding errors, and reduces interviewer's inadvertent failure to ask some interview questions. As a result, only relevant questions are asked, and interview time is reduced. Supervisors listening to real-time telephone interviews while monitoring the CATI interview on their own computer performed random checks of each interviewer's assessment behavior and data-entry accuracy at least twice during each shift. Overall, $16 \%$ of all interviews were monitored by supervisors. When an error was detected, supervisors required its correction and discussed the error with the interviewer after the interview. If the same error was detected again in following interviews, the interviewer was removed from the study. No interviewers had to be removed from this study. The interview was approximately 26.5 minutes in length.

\section{Variables}

Demographic Variables. Demographic variables included race/ethnicity, income, and gender. Prior research ${ }^{9}$ sometimes indicated differential risk associated with Hispanic ethnicity and dichotomous categorization of this subgroup was used. Household income was categorized on a 5-point scale of $\$ 0-\$ 15,000$, $\$ 15,001-\$ 25,000$, \$25,001-\$50,000, \$50,001-\$100,000, and $\$ 100,000+$. For the study sample, household income classifications ranged from 1 to 5 (mean: 2.9 [1.2], corresponding to approximately $\$ 25,000-\$ 50,000$ ).

Prior Traumatic Event Exposure. We used a slightly modified version of the National Women's Study Event History-PTSD module to identify exposure to potentially traumatic events. ${ }^{10}$ Participants were asked if they had been exposed to the following events and during this exposure feared that they would be killed or seriously injured: 1) natural disasters such as major earthquakes, hurricanes (other than the 2004 hurricanes), floods, or tornados; 2) serious accidents at work or in a car; 3 ) being physically attacked with a gun knife, or some other weapon; 4) being attacked without a weapon but with the intent to kill or seriously injure; and 5) being in 
military combat. The number of different events was summed to form a count of different types of exposure (sample range: $0-5$ events, mean: 0.6 [0.9]); however we did not ascertain the number of duplicate exposures within traumatic event type, and we did not ascertain how long ago these events occurred as a result of time limitations associated with the survey.

Social Support. Social support was assessed through a modified version of the Medical Outcomes Study $(\mathrm{MOS})^{11}$ module for the 6 months immediately before the hurricane. Five items measured three aspects of social support: emotional (e.g., "someone available to love you and make you feel wanted"), instrumental (e.g., "someone available to help you if you were confined to bed"), and appraisal (e.g., "someone available to give good advice in a crisis"). Answers for each of the five questions ranged on a 4-point scale from "none of the time" to "all of the time" (sample range: 0-20, mean: 15.9, standard deviation [SD]: 4.8).

Hurricane-Related Impact. Participants' exposure to the 2004 Florida hurricanes was assessed separately. Preliminary analyses of data indicated restriction of range with respect to physical hurricane exposure variables because virtually all participants directly experienced hurricane-force winds from at least one of the four storms. Therefore, relevant exposure variables were selected and involved the number of days one was displaced from one's home (sample range: 0-240, mean: 3.0, SD: 22.5) and incurred dollar losses not covered by insurance, categorized on a five-point scale of $\$ 0-\$ 5,000, \$ 5,001-$ $\$ 20,000, \quad \$ 20,001-\$ 50,000, \$ 50,001-\$ 100,000$, and $\$ 100,001+$ (sample range: $1-4$, mean: $1.3, \mathrm{SD}: 0.7$, corresponding to approximately $\$ 5,000-\$ 10,000$ ).

Positive Outcomes. Five possible positive outcomes of the hurricane were assessed and summed and included the following: made new friends, family brought closer together, found out someone cared for them, became more involved in community, and noticed increased cooperation among neighbors. A simple count of the number of positive outcomes endorsed was used (sample range: 0-5, mean: 1.4, SD: 1.0).

Current Health Status. Three questions were modified from the MOS to assess general health. The first question rated general health on a five-point scale; the second compared current health status before and after the hurricanes on a three-point scale, whereas the third assessed current functional impairment resulting from health on a two-point scale. Scores were summed with lower scores representing better health (sample range: 2-9, mean: 4.8, SD: 1.6).

Posttraumatic Stress Disorder Symptoms. The 17 PTSD symptoms (comprising reexperiencing, avoidance, and hyperarousal clusters) occurring since the hurricanes were measured with the National Women's Study PTSD module, a widely used measure in population-based epidemiologic research originally modified from the Diagnostic Interview Schedule. ${ }^{12}$ (sample range: 0-17, mean: 1.6, SD: 2.8).

Generalized Anxiety Disorder Symptoms. GAD symptoms occurring since the hurricanes were measured using a slightly modified version of the SCID-IV structured interview. ${ }^{13}$ Questions corresponded directly to the six specified DSM-IV symptoms of GAD, including restlessness, fatigue, concentration problems, irritability, tension, and sleep disturbance (sample range: 0-5, mean: 0.5, SD: 1.3$)$.

Major Depression Symptoms. We measured 10 symptoms of depression occurring since the hurricanes through structured interview questions modified from the SCID-IV. These questions targeted depression criteria using yes/no response formats for each DSM-IV symptom (sample range: $0-10$, mean: 1.1, SD: 1.9).

\section{Statistical Analyses}

First, univariate analysis of variance (ANOVA) was conducted for each of the three psychologic outcomes (i.e., symptom levels of PTSD, depression, and GAD) to identify potential age-based differences in symptom prevalence. Next, variables selected on the basis of their relation to psychopathologic outcomes in prior empiric research were subjected to two-tailed bivariate correlational analyses for each age group. Variables that reached a cutoff of $p<0.05$ for each psychopathologic outcome in correlational analyses were entered into hierarchical multiple regression analyses. To control type I error, predictor variables in these regressions were required to attain $\mathrm{p} \leq 0.01$ to be considered statistically significant. Order of entry was based on the temporal manifestation of variables, whereas grouping of entry was 
based on conceptual relationships between variables. Thus, demographic variables were entered on the first step, followed by prehurricane contextual variables of social support and prior exposure to traumatic stressors on step two, followed by hurricane-related variables on step three, followed by current (at the time of assessment) self-ratings of health status on step four. As mentioned, these regressions were conducted separately for each age group. However, to test direct age $\times$ risk factor interactions, a final set of regressions was conducted on the combined data set of older and younger adults. Note that in these final analyses, type I error was controlled by: 1) using only risk factors identified as significant in the aforementioned regressions; and 2) requiring $\mathrm{p} \leq 0.01$. The SPSS version 12 statistical package was used for all analyses.

\section{RESULTS}

\section{Sample}

Of the 1,130 older adult participants, 727 (64.5\%) were women and 401 (35.5\%) were men; for younger participants, 257 (63\%) were women and 151 (37\%) were men; gender data were not available for two older and five younger participants. The mean age of each group was 71.0 years (SD: 7.9) and 42.9 years (SD: 10.5). The racial/ethnic distribution for the older adult group was as follows: 1,012 (92.0\%) white, 56 (5.1\%) black, $12(1.1 \%)$ Asian or Pacific Islander, and 20 (1.8\%) Native American or Alaskan. For younger adults, $342(84.6 \%)$ were white, 45 (11.1\%) black, 11 (2.7\%) Asian or Pacific Islander, and six Native American or Alaskan (1.6\%). Race data were missing from 30 participants. Hispanic ethnicity was endorsed by 48 older adults (4.3\%) and $32(7.7 \%)$ younger adults. Hispanic ethnicity data were missing from 14 participants. Considering the entire sample, the overall cooperation rate (i.e., [completes + screenouts] divided by [completes + screenouts + refusals before screen + qualified refusals]) was $70 \%$. The response rate among eligible individuals (i.e., completes divided by [completes + qualified refusals]) was $81 \%$.

\section{Comparison of Symptom Level by Age Group: Posttraumatic Stress Disorder, Depression, Generalized Anxiety Disorder}

Table 1 provides the ANOVA results comparing older and younger adults. Younger adults reported significantly higher symptom levels of PTSD (mean: 2.2 [3.3] younger versus 1.4 [2.5] older), depression (mean: 1.3 [2.2] younger versus 1.0 [1.8] older), and GAD (mean: 0.6 [1.5] younger versus 0.4 [1.2] older). Note that although the overall mean numbers of symptoms reported is low and in the subclinical range, this represents symptoms distributed across the entire sample, not only among individuals diagnosed with the disorder in question.

\section{Bivariate Analyses}

We selected an initial set of potential risk variables based on their theoretical and empiric relation to PTSD, depression, and GAD. Correlation tables for all variables by each age group are available from the first author. For younger adults, higher PTSD symptom levels were associated ( $\mathrm{p}<0.05$ ) with Hispanic ethnicity, lower income, lower social support, greater exposure to different types of prior traumatic events, and health problems. Depression and GAD symptom levels were correlated with these variables as well, with the exceptions of: 1) female gender being associated with increased depression and GAD symptoms; and 2) Hispanic ethnicity being unrelated to these outcomes. For older adults, higher PTSD, depression, and GAD symptom levels were all significantly associated with Hispanic ethnicity, lower

\begin{tabular}{|c|c|c|c|c|}
\hline Source & df & $\mathbf{F}$ & $\boldsymbol{\eta}$ & $\mathbf{p}$ \\
\hline \multicolumn{5}{|l|}{ PTSD } \\
\hline Age & 1 & 24.6 & 0.14 & 0.000 \\
\hline Within-group error & 1541 & $(7.5)$ & & \\
\hline \multicolumn{5}{|l|}{ Depression } \\
\hline Age & 1 & 6.5 & 0.06 & 0.011 \\
\hline Within-group error & 1541 & (3.6) & & \\
\hline \multicolumn{5}{|l|}{ GAD } \\
\hline Age & 1 & 5.6 & 0.06 & 0.018 \\
\hline Within-group error & 1541 & (1.7) & & \\
\hline
\end{tabular}

Note: Values enclosed in parentheses represent mean square errors. 
income, lower social support, prior traumatic events, number of days displaced after the storm, out-ofpocket storm damage expenses, and health problems. However, higher PTSD and GAD symptoms were also associated with lower numbers of positive outcomes, whereas higher depressive symptoms were associated with female gender.

\section{Multivariate Analyses}

Statistically significant variables from bivariate analyses were used in regression analyses, which are given for each age group in Table 2. For younger adults, the final models for PTSD, depression, and GAD accounted for $21 \%, 29 \%$, and $16 \%$ of the variances, respectively. For all three disorders, significant predictors in the final model for younger adults included social support, prior traumatic event exposure, and health problems. Female gender was associated with depression and GAD. No storm-related variables were associated with symptoms for any disorder for younger adults.

Table 2 also provides corresponding regressions for older adults. Variance accounted for by predictor sets for PTSD, depression, and GAD symptoms was $23 \%, 23 \%$, and $12 \%$, respectively. Like with younger adults, social support, prior exposure to different types of traumatic events, and health status were significantly associated with PTSD and depression in the final regression model. In contrast to younger adults, lower income was also associated with PTSD. Similarly, contrasting with findings for younger adults was the significant relation of psychopathology to storm-related variables in older participants, particularly the number of days displaced from one's home and out-of-pocket expenses.

\section{Risk Factor by Age Interaction Analyses}

As is evident, the aforementioned regressions within each age group produced some overlapping risk factors and some risk factors unique to one or the other age group. However, to facilitate comment on age-based differences in risk factors, direct statistical analysis of the interaction between age and a given risk factor is necessary. Thus, we conducted follow-up regression analyses using the entire data set of older and younger adults (rather than using one or the other age group, as was done previously) examining the age group $\times$ risk factor interaction terms. We controlled type I error inflation by 1) conducting these regressions only for risk factors determined to be unique to one or the other age groups in initial regression equations above, and by 2 ) requiring $p \leq 0.01$. For PTSD, statistically significant risk factors occurring in one age group but not the other included Hispanic ethnicity (younger adults only), income (older adults only), and number of days displaced (older adults only). For depression, significant risk factors unique to one or the other age groups included only number of days displaced (older adults). Finally, for GAD, unique risk factors included gender (younger adults), income (older adults), number of days displaced (older adults), and out-of-pocket expenses (older adults).

Table 3 provides the regressions statistics for these interaction analyses. For PTSD, the interaction between age and each of the unique risk factors (ethnicity, income, number of days displaced) was significant, indicating that age-based differences in risk factors for this disorder were present. Similarly, for depression, the interaction between age and number of days displaced was also significant. Finally, for $\mathrm{GAD}$, the unique risk factor gender did not significantly interact with age to determine outcome, whereas the risk factors income, days displaced, and out-of-pocket expenses did significantly interact with age to determine outcome.

\section{CONCLUSIONS}

Clear differences in risk factor sets emerged between older and younger adults, and these risk factor sets accounted for large proportions of the variance in symptom outcome. Notably, the relative importance of specific demographic- and stormrelated variables appeared to vary by age group. For example, regression analyses revealed that Hispanic ethnicity was associated with PTSD symptoms only in younger adults. Moreover, findings relating to age-based correlates of income and storm exposure appear to have important implications for postdisaster mental health. Specifically, income was not associated with any psycho- 
TABLE 2. Regression Analyses Predicting Psychopathologic Outcomes for Younger and Older Adults

\begin{tabular}{|c|c|c|c|c|c|c|}
\hline \multirow[b]{2}{*}{ Variable } & \multicolumn{3}{|c|}{ Younger Adults } & \multicolumn{3}{|c|}{ Older Adults } \\
\hline & $\mathbf{B}$ & SE B & $\mathbf{p}$ & $\mathbf{B}$ & SE B & $\mathbf{p}$ \\
\hline \multicolumn{7}{|l|}{ PTSD } \\
\hline \multicolumn{7}{|l|}{ Step 1} \\
\hline Non-Hispanic & -1.10 & 0.56 & -0.09 & -0.33 & 0.44 & -0.02 \\
\hline Income & -0.04 & 0.15 & -0.01 & -0.21 & 0.08 & $-0.09^{*}$ \\
\hline \multicolumn{7}{|l|}{ Step 2} \\
\hline Social support & -0.14 & 0.04 & $-0.18^{* *}$ & -0.11 & 0.02 & $-0.19^{* * *}$ \\
\hline Prior trauma & 0.86 & 0.15 & $0.28^{* *}$ & 0.62 & 0.10 & $0.20^{* * *}$ \\
\hline \multicolumn{7}{|l|}{ Step 3} \\
\hline No. of days displaced & - & - & - & 0.02 & 0.00 & $0.13^{* *}$ \\
\hline Positive outcomes & - & - & - & 0.13 & 0.09 & 0.05 \\
\hline Out-of-pocket expenses & - & - & - & 0.14 & 0.08 & 0.06 \\
\hline \multicolumn{7}{|l|}{ Step 4} \\
\hline Health problems & 0.50 & 0.11 & $0.23^{* *}$ & 0.41 & 0.06 & $0.24^{* *}$ \\
\hline \multicolumn{7}{|l|}{ Depression } \\
\hline \multicolumn{7}{|l|}{ Step 1} \\
\hline Non-Hispanic & - & - & - & -0.11 & 0.30 & -0.01 \\
\hline Female & 0.77 & 0.20 & $0.17^{* *}$ & 0.25 & 0.12 & 0.07 \\
\hline Income & 0.00 & 0.10 & 0.00 & -0.08 & 0.06 & -0.05 \\
\hline \multicolumn{7}{|l|}{ Step 2} \\
\hline Social support & -0.13 & 0.03 & $-0.24^{* *}$ & -0.07 & 0.01 & $-0.18^{* * *}$ \\
\hline Prior trauma & 0.42 & 0.10 & $0.20^{* *}$ & 0.22 & 0.07 & $0.11^{*}$ \\
\hline \multicolumn{7}{|l|}{ Step 3} \\
\hline No. of days displaced & - & - & - & 0.01 & 0.00 & $0.13^{\text {** }}$ \\
\hline Out-of-pocket expenses & - & - & - & 0.05 & 0.05 & 0.03 \\
\hline \multicolumn{7}{|l|}{ Step 4} \\
\hline Health problems & 0.49 & 0.07 & $0.33^{* *}$ & 0.37 & 0.04 & $0.32^{* *}$ \\
\hline \multicolumn{7}{|l|}{ Generalized anxiety disorder } \\
\hline \multicolumn{7}{|l|}{ Step 1} \\
\hline Non-Hispanic & - & - & - & -0.32 & 0.22 & -0.05 \\
\hline Female & 0.45 & 0.15 & $0.15^{*}$ & 0.14 & 0.09 & 0.06 \\
\hline Income & -0.03 & 0.07 & -0.01 & -0.10 & 0.04 & $-0.09^{*}$ \\
\hline \multicolumn{7}{|l|}{ Step 2} \\
\hline Social support & -0.06 & 0.02 & $-0.16^{*}$ & -0.02 & 0.01 & -0.08 \\
\hline Prior trauma & 0.31 & 0.07 & $0.21^{* *}$ & 0.12 & 0.05 & 0.09 \\
\hline \multicolumn{7}{|l|}{ Step 3} \\
\hline No. of days displaced & - & - & - & 0.01 & 0.00 & $0.16^{* *}$ \\
\hline Positive outcomes & - & - & - & 0.07 & 0.04 & 0.06 \\
\hline Out-of-pocket expenses & - & - & - & 0.10 & 0.04 & $0.10^{*}$ \\
\hline \multicolumn{7}{|l|}{ Step 4} \\
\hline Health problems & 0.20 & 0.05 & $0.20^{*}$ & 0.10 & 0.03 & $0.13^{* *}$ \\
\hline
\end{tabular}

Notes: Younger adults: For PTSD analysis, $\mathrm{R}^{2}=0.03$ for step $1(\mathrm{p}<0.01) ; \mathrm{R}^{2}=0.14$ for step $2(\mathrm{p}<0.001)$;) $\mathrm{R}^{2}=0.05$ for step 4 (p $\left.<0.001\right)$. Final model $\mathrm{R}^{2}=0.21$. For depression analysis, $\mathrm{R}^{2}=0.05$ for step $1(\mathrm{p}<0.001) ; \mathrm{R}^{2}=0.14$ for step $2(\mathrm{p}<0.001) ; \mathrm{R}^{2}=0.10$ for step $4(\mathrm{p}<0.001)$. Final model $\mathrm{R}^{2}=0.29$. For GAD analysis, $\mathrm{R}^{2}=0.03$ for step $1(\mathrm{p}<0.01) ; \mathbf{R}^{2}=0.09$ for step $2(\mathrm{p}<0.001)$; $\mathrm{R}^{2}=0.04$ for step 4 (p $\left.<0.001\right)$. Final model $\mathrm{R}^{2}=0.16$.

Older adults: For PTSD analysis, $R^{2}=0.03$ for step $1(p<0.001) ; R^{2}=0.11$ for step $2(p<0.001) ; R^{2}=0.04$ for step $3(p<0.001) ; R^{2}=0.05$ for step $4(p<0.001)$. Final model $R^{2}=0.23$. For depression analysis, $R^{2}=0.03$ for step $1(p<0.001) ; R^{2}=.07$ for step $2(p<0.001) ; R^{2}=0.03$ for step $3(\mathrm{p}<0.001) ; \mathrm{R}^{2}=0.09$ for step $4(\mathrm{p}<0.001)$. Final model $\mathrm{R}^{2}=0.23$. For $\mathrm{GAD}$ analysis, $\mathrm{R}^{2}=0.03$ for step $1(\mathrm{p}<0.001)$; $\mathrm{R}^{2}=0.02$ for step $2(\mathrm{p}<0.001) ; \mathrm{R}^{2}=0.05$ for step $3(\mathrm{p}<0.001) ; \mathrm{R}^{2}=0.01$ for step $4(\mathrm{p}<0.05)$. Final model $\mathrm{R}^{2}=0.12$

${ }^{*} \mathrm{p}<0.01 ;{ }^{* *} \mathrm{p}<0.001$.

SE: standard error; PTSD: posttraumatic stress disorder; GAD: generalized anxiety disorder

logic outcome for younger adults, but predicted two of three symptom domains for the elderly. Similarly, postinsurance dollar losses and the number of days displaced from one's home predicted psychopathology in older adults but were unrelated to psychopathology in younger adults. These economic-based differences may reflect greater psychologic distress secondary to actual financial diffi- 


\begin{tabular}{|c|c|c|c|}
\hline \multicolumn{4}{|c|}{$\begin{array}{l}\text { Regression Analyses of Interaction Terms: Age } \times \\
\text { Risk Factors }\end{array}$} \\
\hline Variable & B & SE B & \\
\hline \multicolumn{4}{|l|}{ PTSD regressions } \\
\hline Age $\times$ number of days displaced & 0.01 & 0.00 & $0.07^{*}$ \\
\hline Age $\times$ non-Hispanic ethnicity & -0.46 & 0.07 & $-0.16^{* *}$ \\
\hline Age $\times$ income & -0.23 & 0.04 & $-0.18^{* *}$ \\
\hline \multicolumn{4}{|l|}{ Depression regressions } \\
\hline Age $\times$ number of days displaced & 0.00 & 0.00 & $0.08^{*}$ \\
\hline \multicolumn{4}{|l|}{ GAD regressions } \\
\hline Age $\times$ number of days displaced & 0.00 & 0.00 & $0.10^{\text {*** }}$ \\
\hline Age $\times$ female gender & & 0.02 & 0.03 \\
\hline Age $\times$ income & -0.07 & 0.02 & $-0.12^{\text {** }}$ \\
\hline Age $\times$ out-of-pocket expenses & 0.07 & 0.02 & $0.12^{* *}$ \\
\hline \multicolumn{4}{|c|}{$\begin{array}{l}\text { Note: Each regression is independent of the others. } \\
{ }^{*} \mathrm{p}<0.01 ;{ }^{* *} \mathrm{p}<0.001 \text {. } \\
\text { SE: standard error; PTSD: posttraumatic stress disorder; GAD: gen- } \\
\text { eralized anxiety disorder. }\end{array}$} \\
\hline
\end{tabular}

culties experienced by older adults in this country. That is, a relatively larger proportion of elders are on fixed incomes and may not have the capacity to increase their earnings to manage unexpected postdisaster expenses. This may lead to a sense of hopelessness and related reactions of anxiety and depression.

Some similarities in risk factors between age groups also were evident. For example, several variables were universally predictive of symptoms for both older and younger participants, including low social support, prior exposure to severe traumatic events, and poor health status. This is consistent with previous research and speaks to the potential utility of community-based efforts aimed at increasing social support and addressing basic healthcare needs after natural disasters. ${ }^{14}$

Several weaknesses of this research warrant mention apart from concerns associated with any survey study (e.g., limited generalizability resulting from sampling derived only from households with telephones, exclusive reliance on self-report data). Specifically, statistical power differed across age groups because the comparison sample of younger adults was significantly smaller than that of older adults. However, repeating analyses using a relatively more liberal inclusion cutoff significance level of $p<0.10$ in initial correlations did not alter the ultimate predictive models for any disorder (i.e., the predictor set in all multiple regressions did not change).
Another potential weakness involved combining younger adults (i.e., 18-39 years) and middle-aged adults (i.e., 40-59 years) to form the comparison group. Previous research noted some differences between these two age groups, with middle-aged participants at greater risk of PTSD relative to younger and older adults. ${ }^{15}$ This increased risk has been attributed to the "burden of middle age" or the fact that this age group bears most of the ultimate financial and operative responsibility for dealing with the aftermath of disasters and severe life stressors. However, this age-based finding has not been consistently observed. ${ }^{6}$ Indeed, in the present sample, younger and middle-aged adults did not significantly differ on any outcome variable. Moreover, when analyses were repeated using only the middle-aged members as the comparison group (i.e., the younger adults were dropped), an identical predictor set emerged for all six regressions, and variance accounted for by the model was preserved. Taken together, these two post hoc analyses indicate that our findings are both stable and robust.

Consistent with earlier research, it appears that older adults are more resilient than younger adults with regard to mental health outcomes after natural disasters such as the 2004 Florida hurricanes. This age-based resiliency may represent enhanced coping skills that accompany aging, a reluctance to report psychologic symptoms, or the effects of selective mortality and morbidity on sampling (i.e., individuals who are less resilient may have shorter lifespans and hence would be available in smaller proportions for the older adult sample). ${ }^{2}$ Whereas several similarities in risk factors were evident across age groups, important differences also emerged. Specifically, risk factors that involved financial difficulties were particularly relevant to older adults and indicate that the economic needs of this age group after natural disasters are linked to their psychologic well-being. As such, amelioration of the financial burden experienced by disaster-affected elders on fixed incomes is a potentially useful area of focus for systemwide responses to these types of events.

This research was supported by NIMH RAPID Grant MH05220-01A2 (Principal Investigator: Ron Acierno, Ph.D.). Views in this article do not necessarily represent those of the agency supporting this research. 


\section{References}

1. Acierno R, Brady K, Gray M, et al: Psychopathology following interpersonal violence: a comparison of risk factors in older and younger adults. J Clin Geropsychol 2002; 8:13-23

2. Norris F: Epidemiology of trauma: frequency and impact of different potentially traumatic events on different demographic groups. J Consult Clin Psychol 1992; 60:409-418

3. Centers for Disease Control and Prevention: Rapid assessment of the needs and health status of older adults after Hurricane Charley-Charlotte, DeSoto, and Hardee Counties, Fla. Aug 27-31, 2004. MMWR Morb Mortal Wkly Rep 2004; 53:837-840

4. Norris FH, Friedman MJ, Watson PJ, et al: 60,000 disaster victims speak: part I. An empirical review of the empirical literature, 1981-2001. Psychiatry 2002; 65:207-239

5. Galea S, Resnick H, Ahern J, et al: Posttraumatic stress disorder in Manhattan, N.Y., after the Sept 11th terrorist attacks. J Urban Health 2002; 79:340-353

6. Norris F, Kaniasty K, Conrad M, et al: Placing age differences in cultural context: a comparison of the effects of age on PTSD after disasters in the United States, Mexico, and Poland. J Clin Geropsychol 2002; 8:153-173

7. Galea S, Ahern J, Resnick H, et al: Psychological sequelae of the Sept 11 terrorist attacks in New York City. N Engl J Med 2002; 346:982-987

8. NOAA: Data From the National Weather Service/National Hurricane Center Contributing to Palm Beach Post article Florida's
Summer of Storms. 2004. Available at: http://www.palmbeachpost. com/storm/content/weather/special/storm/2004/atlantic/. Accessed February 2005

9. Ruef AM, Litz BT, Schlenger WE: Hispanic ethnicity and risk for combat-related posttraumatic stress disorder. Cultur Divers Ethni Minor Psychol 2000; 6:235-251

10. Kilpatrick DG, Resnick HS, Saunders B, et al: National Women's Study event history-PTSD module, in Measurement of Stress, Trauma, and Adaptation. Edited by Stamm BH. Lutherville, MD, Sidran Press, 1996, pp. 214-217

11. Sherbourne CD, Stewart AL: The MOS social support survey. Soc Sci Med 1991; 32:705-714

12. Kilpatrick DG, Resnick HS, Saunders BE, et al: The National Women's Study PTSD Module. Charleston, SC, Department of Psychiatry \& Behavioral Sciences, Medical University of South Carolina, 1989

13. Spitzer RL, Williams J, Gibbon M, et al: Structured Clinical Interview for DSM-IV. Washington, DC, American Psychiatric Press, 1995

14. Norris F, Kaniasty K: Received and perceived social support in times of stress: as test of the social support deterioration deterrence model. J Pers Soc Psychol 1996; 71:498-511

15. Thompson M, Norris F, Hanacek B: Age differences in the psychological consequences of hurricanes. Psychol Aging 1993; 8:606-616 